RBMC

ISSN 2447-9071

doi https://doi.org/10.36414/rbmc.v7i19.114

\title{
Qualidade microbiológica de cosméticos industrializados: estudo experimental com bases faciais líquidas
}

\section{Microbiological quality of industrialized cosmetics: experimental study with liquid foundation}

Lorena Rocha Martins Gomes' , Nikary Stefany Paula Santos',

Alessandra Marques Cardoso $0^{1,2,3}$

\author{
'Pontifícia Universidade Católica de Goiás - PUC Goiás \\ ${ }^{2}$ Faculdade da Polícia Militar - FPM \\ ${ }^{3}$ Secretaria de Estado da Saúde de Goiás - SES-GO
}

\section{Resumo}

Devido à introdução crescente e diária de cosméticos no mercado, alguns microrganismos inevitavelmente passam despercebidos em baixos níveis de contaminação. Este trabalho objetivou realizar análises microbiológicas de bases faciais cosméticas líquidas e industrializadas. Foram adquiridas 11 amostras de bases faciais líquidas de diferentes indústrias cosméticas, comercializadas em Goiânia-GO. As bases foram analisadas seguindo uma metodologia adaptada da Farmacopeia Brasileira e da RDC/ ANVISAN 481, de 23 de setembro de 1999, conforme dispõe o controlemicrobiológico de produtos cosméticos. As análises consistiram na pesquisa e contagem total de microrganismos mesófilos aeróbios totais, coliformes totais e termotolerantes, bolores eleveduras, Staphylococcus aureus, Pseudomonas aeruginosa e Escherichia coli. Todos os testes foram realizados em duplicata, por meio do método de semeadura em superfície. Sobre a pesquisa de S. aureus, P. aeruginosa, E. coli e coliformes, observouse resultados negativos nas 11 (100,0\%) amostras analisadas. Contudo, em duas (18,2\%) amostras foi observada contagem total de microrganismos mesófilos aeróbios acima do limite permitido pela legislação brasileira, que é de $5 \times 10^{2} \mathrm{UFC} / \mathrm{g}$. As análises micológicas revelaram crescimento fúngico em 10 (90,9\%) amostras, embora estivessem com a contagem de colônias abaixo do limite máximo considerado aceitável pela ANVISA. Este estudo evidenciou a necessidade de garantir a qualidade e a higiene das bases cosméticas faciais líquidas industrializadas. Em sua maioria, as amostras apresentaram adequado controle da qualidade microbiológico, contudo, vale ressaltar a importância da adoção de melhorias por parte das indústrias quanto ao cumprimento das boas práticas de fabricação. Palavras-chave: Microbiologia; Contaminação Biológica; Controle de Qualidade.

Contato para correspondência: Alessandra Marques Cardoso

E-mail:

alemarquespuc@gmail.com

Conflito de interesse: Não

Financiamento: Recursos próprios

Recebido: 23/11/2021

Aprovado: 10/12/2021

\begin{abstract}
Due to the daily increasing introduction of cosmetics on the market, some microorganisms inevitably go unnoticed at low levels of contamination. This work aims to carry out microbiological analyzes of liquid and industrialized cosmetic facial bases. Eleven samples of liquid facial foundations from different cosmetic industries, commercialized in Goiânia-GO, were acquired. The liquid facial was analyzed following a methodology adapted from the Brazilian Pharmacopoeia and RDC of ANVISA number 481 , of September 23, 1999, as provided for the microbiological control of cosmetic products. The analysis consisted of research and the total count of the mesophilictotal aerobicmicroorganisms, total coliforms, thermotolerant, molds and yeast, Staphylococcus aureus, Pseudomonas aeruginosa and Escherichia coli. All tests were performed in duplicate, using the superficial sowing method. Regarding the investigation of S. aureus, P. aeruginosa, E. coliand coliforms, negative results were observed in the 11 (100.0\%) samples analyzed. However, in two (18,2\%) samples a total count of aerobicmesophilicmicroorganisms was observed above the limitallowed by Brazilian legislation, which is from $5 \times 10^{2} \mathrm{UFC} / \mathrm{g}$.
\end{abstract}


Mycological analyzes revealed fungal growth in 10(90.9\%) of the samples, although they were with the count below the limit minimum considered acceptable by ANVISA. The present study highlighted the need to guarantee the quality and hygiene of industrialized liquid facial cosmetic foundations. Most of the samples showed adequate microbiological quality control, however, it is worth emphasizing the importance of the adoption of improvements by the industries regarding compliance with good manufacturing practices.

Keywords: Microbiology; Biological Contamination; Quality control.

\section{Introdução}

Há aproximadamente 30.000 anos os produtos cosméticos surgiram na Ásia, entretanto a sua primeira utilização ocorreu no antigo Egito, onde as pessoas pintavam os olhos para evitar a contemplação direta do Deus Sol. O conceito de cosméticos vem do grego kosmostikos, e significa poder e habilidade de decorar, retratando a finalidade da sua utilização no passado, que era basicamente ornamentação, cultos aos deuses e camuflagem como proteção em guerras ${ }^{1-3}$.

A indústria de cosméticos tem sido de grande importância na economia de grande parte dos países desenvolvidos, incluindo o Brasil que atingiu a marca de 29,62 bilhões de dólares em 2019, se tornando então o quarto maior mercado mundial, seguindo atrás somente dos Estados Unidos, China e Japão. O país representa metade desse setor na América Latina e mesmo com a crise causada pelo coronavírus em 2020, se manteve em alta. Os cosméticos são exportados a 174 países, sendo a Argentina responsável por quase um quarto $(24,8 \%)$ do valor exportado em $2020^{4}$.

A produção e a comercialização destes produtos têm oferecido resultados promissores aos profissionais desse setor. Consequentemente, com o crescimento deste mercado, as indústrias passaram a diversificar seus produtos, reformulando a composição, a rotulagem, e passando a ter maior preocupação com os consumidores ${ }^{4,5}$.

Os cosméticos industrializados podem apresentar caráter químico ou natural, e são destinados à proteção ou embelezamento de diferentes regiões do corpo. Podem ser classificados como cosméticos de superfície, cosméticos de profundidade, cosméticos de decoração e adorno, cosméticos de limpeza e de tratamento ${ }^{6}$. Embora a sua classificação seja estabelecida no quadro de "produtos de saúde", a maioria desses produtos estão classificados como produtos farmacêuticos não estéreis, podendo então sofrer contaminação por microrganismos.

A qualidade e a segurança devem ser garantidas através das exigências estabelecidas pela Agência Nacional de Vigilância Sanitária (ANVISA), cuja responsabilidade compreende a implementação de normas de Boas Práticas de Fabricação e Controle de Qualidade, regidas pela RDC no. 48/2013, ga- rantindo qualidade e segurança na utilização dos produtos cosméticos ${ }^{8,9}$.

O controle microbiológico dos produtos cosméticos é de suma importância, uma vez que envolve qualidade e segurança para os usuários ${ }^{10}$. Para proteger e prevenir a qualidade dos produtos, substâncias conservantes são empregadas, mantendo assim, a carga microbiana dentro do padrão estabelecido, protegendo-os contra a contaminação bacteriana e fúngica, correspondendo aos microrganismos mais comuns presentes ${ }^{3}$.

Porém, apesar dos cuidados para a fabricação segura, os conservantes não apresentam uma segurança conclusiva, podendo surgir microrganismos na manipulação e até mesmo durante o uso pelo consumidor. Cabe também atenção quanto às embalagens, sendo que estas podem promover proteção ou desproteção do produto ${ }^{11,12}$.

O surgimento de microrganismos ocorre devido aos produtos serem substratos e apresentarem nutrientes, como água, vitaminas, lipídios, dentre outros, proporcionando assim, um ambiente ideal para o seu crescimento e proliferação. Os principais microrganismos que podem ser patogênicos e apresentarem riscos à saúde humana são Pseudomonas aeruginosa e Staphylococcus aureus ${ }^{13,14}$.

Em virtude da introdução crescente e diária de cosméticos no mercado, alguns microrganismos inevitavelmente passam despercebidos em baixos níveis de contaminação3. Dessa forma, o objetivo deste trabalho foi realizar análises microbiológicas de bases faciais cosméticas líquidas e industrializadas, de acordo com a RDC da ANVISA No 481, de 23 de setembro de $1999^{15}$.

\section{Métodos}

Foram adquiridas 11 amostras de bases cosméticas faciais líquidas de diferentes indústrias cosméticas, comercializadas em Goiânia-GO. Dentre as bases utilizadas, foram adquiridas marcas bastante consumidas pela população, bem como outras pouco difundidas no mercado. As bases foram enumeradas de 01 a 11, e analisadas seguindo uma metodologia adaptada da Farmacopeia Brasileira, 6 a edição, de 12 de agosto 
de $2019^{16}$ e da RDC da ANVISA N ${ }^{\circ}$ 481, de 23 de setembro de $1999^{15}$, conforme dispõe o controle microbiológico de produtos cosméticos.

Os experimentos foram conduzidos no Laboratório Clínico da Pontifícia Universidade Católica de Goiás (LAC/PUC Goiás), seguindo todas as normas de biossegurança. Com relação aos critérios éticos e legais, não houve necessidade de submeter o projeto a um comitê de ética e pesquisa, uma vez que não foram utilizadas amostras humanas e/ou animais. Contudo, foram preservadas as identidades das indústrias de cosméticos cujas bases faciais líquidas foram testadas.

Todos os materiais utilizados nos experimentos foram submetidos previamente ao processo de esterilização, empregando o uso de autoclave, por meio de calor úmido sob pressão, à temperatura de $121^{\circ} \mathrm{C}$, durante 15 minutos. O manuseio de todas as amostras e materiais utilizados durante os procedimentos microbiológicos foram realizados em uma cabine de segurança biológica classe II. As bases foram adquiridas com embalagens plásticas lacradas e com tampas de rosca, sendo desinfetadas de acordo com os procedimentos operacionais padrões (POP) descritos na Farmacopeia Brasileira, 6a edição, de 12 de agosto de 201916, utilizando o etanol a 70\% ${ }^{15,17}$.

Para o preparo das amostras foram diluídos $1 \mathrm{~g}$ de base facial cosmética em $8,8 \mathrm{~mL}$ de $\mathrm{NaCl}$ a 0,85\% estéril. A diluição teve como objetivo a neutralização dos conservantes inibidores do crescimento microbiano presentes nas amostras que pudessem interferir nas análises. Logo, por se tratar de amostras que possuem em sua composição produtos de natureza lipídica, foram acrescentados 0,2 mL de Polissorbato 20 estéril, um agente tensoativo não aniônico, adotando-se uma diluição de 1:10. Posteriormente, as amostras foram submetidas à temperatura de $45^{\circ} \mathrm{C}$ por 30 minutos até a formação de uma emulsão, o que auxiliou na clivagem das substâncias gordurosas que porventura estivessem presentes (Figura 1) 15,18,19.

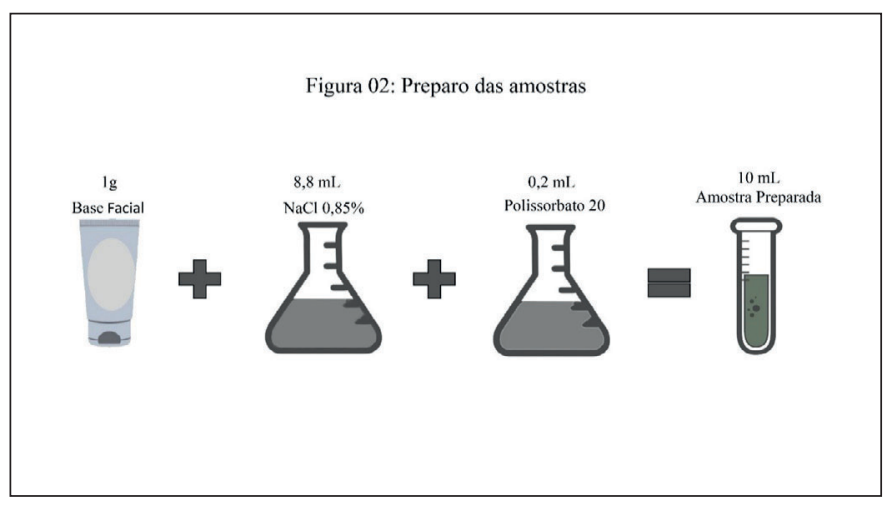

Figura 1. Processo de diluição e neutralização dos conservantes das bases faciais líquidas.
As análises consistiram na pesquisa e contagem total de microrganismos mesófilos aeróbios totais, coliformes totais e termotolerantes, bolores e leveduras, Staphylococcus aureus, Pseudomonas aeruginosa e Escherichia coli. Todos os testes foram realizados em duplicata, por meio do método de semeadura em superfície dos meios de cultura ${ }^{15,17}$.

Para a contagem de microrganismos mesófilos aeróbios totais, foram semeados 0,1 mL das amostras preparadasnoÁgarPlate Count Agar (PCA) e incubadas à temperatura de $35^{\circ} \mathrm{C}$, sendo as leituras das placas realizadas no terceiro, quarto e quinto dia de incubação.

Para a contagem de bolores e leveduras, foram semeados na superfície das placas de ágar Sabouraud Dextrose, 0,1 mL da amostra preparada. As placas foram incubadas à temperatura ambiente, sendo as leituras realizadas no quinto, sexto e sétimo dia de incubação. As colônias fúngicas isoladas foram identificadas por meio do estudo das suas características macromorfológicas e micromorfológicas, pela técnica do esgarçamento de alça com lactofenol azul de algodão.

Para a pesquisa e contagem de S. aureus, P.aeruginosa, E. coli, coliformes totais e termotolerantes, um volume de $0,5 \mathrm{~mL}$ das amostras preparadas foram previamente incubadas em $4,5 \mathrm{~mL}$ de caldo de enriquecimento Brain Heart Infusion Broth (caldo BHI), tendo como volume final $5 \mathrm{~mL}$ (diluição equivalente a 1:20) em estufa microbiológica, sob temperatura de $35^{\circ} \mathrm{C}$, por um período de 24 horas $^{20}$.

Após esse período, realizou-se a semeadura de $0,1 \mathrm{~mL}$ do caldo $\mathrm{BHI}$ na superfície de cada um dos ágares: Manitol-sal (para pesquisa de S. aureus), MacConkey (para pesquisa de $P$. aeruginosa, E. coli, coliformes totais e termotolerantes) e Eosin Methylene Blue -EMB (para pesquisa de E. coli, coliformes totais e termotolerantes). Após semeadura, as placas de Manitol-sal, MacConkey e EMB foram incubadas à temperatura de $35^{\circ} \mathrm{C}$, sendo as leituras realizadas com 24 horas, 48 horas e 72 horas. A Figura 2 apresenta um resumo esquemático do protocolo adotado para a semeadura das amostras nos meios de cultura.

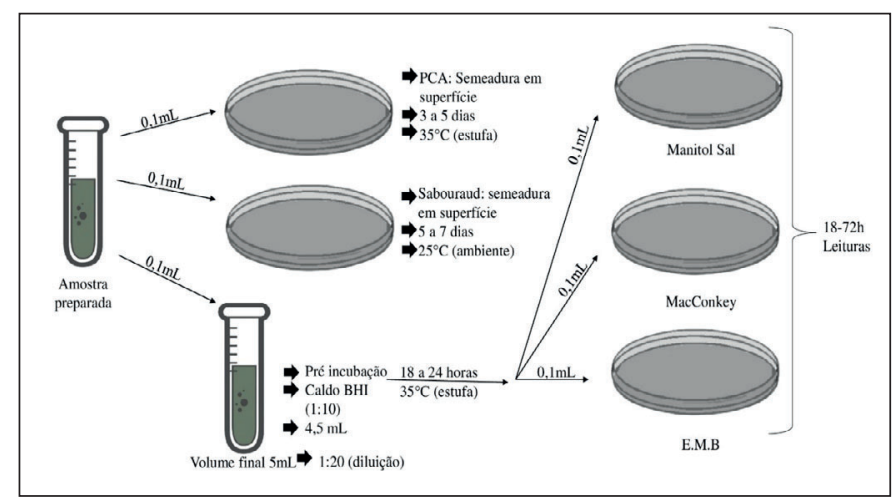

Figura 2. Preparo das culturas para contagem total dos microrganismos em seus respectivos ágares pelo método de semeadura em superfície. 


\section{Resultados}

Em relação à pesquisa de $S$. aureus, $P$. aeruginosa, $E$. coli e coliformes, observou-se resultados negativos nas 11 (100,0\%) amostras analisadas. Contudo, em duas (18,2\%) amostras foi observada contagem total de microrganismos mesófilos aeróbios acima do limite permitido pela legislação brasileira, que é de $5 \times 102$ UFC/g Os resultados das análises bacteriológicas encontram-se apresentados na Tabela 1.

Tabela 1. Resultados das análises bacteriológicas de bases faciais cosméticas líquidas e industrializadas, comercializadas em Goiânia, GO.

\begin{tabular}{|c|c|c|c|c|c|c|c|}
\hline Bases Faciais & $\begin{array}{l}\text { Atendimento a } \\
\text { Legislação } \\
\text { Brasileira }\end{array}$ & $\begin{array}{l}\text { Contagem total de } \\
\text { microrganismos } \\
\text { mesófilos aeróbios } \\
(\mathrm{UFC} / \mathrm{g})\end{array}$ & $\begin{array}{l}\text { Pesquisa de bolores } \\
\text { e leveduras } \\
\text { (UFC/g) }\end{array}$ & $\begin{array}{l}\text { Pesquisa de } \\
\text { coliformes } \\
\text { (UFC/g) }\end{array}$ & $\begin{array}{c}\text { Pesquisa de } \\
\text { Staphylococcus } \\
\text { (UFC/g) }\end{array}$ & $\begin{array}{l}\text { Pesquisa de } \\
\text { Pseudomonas } \\
\text { aeruginosa } \\
\text { (UFC/g) }\end{array}$ & $\begin{array}{c}\text { Pesquisa } \\
\text { de Escherichia coli } \\
\text { (UFC/g) }\end{array}$ \\
\hline 1 & Sim & 25 & 10 & Negativa & Negativa & Negativa & Negativa \\
\hline 2 & Sim & 30 & 20 & Negativa & Negativa & Negativa & Negativa \\
\hline 3 & Sim & 10 & 60 & Negativa & Negativa & Negativa & Negativa \\
\hline 4 & Sim & 15 & 40 & Negativa & Negativa & Negativa & Negativa \\
\hline 5 & Sim & 20 & 20 & Negativa & Negativa & Negativa & Negativa \\
\hline 6 & Sim & 315 & 0 & Negativa & Negativa & Negativa & Negativa \\
\hline 7 & Sim & 30 & 10 & Negativa & Negativa & Negativa & Negativa \\
\hline 8 & Sim & 50 & 05 & Negativa & Negativa & Negativa & Negativa \\
\hline 9 & Não & 3140 & 20 & Negativa & Negativa & Negativa & Negativa \\
\hline 10 & Não & 1020 & 60 & Negativa & Negativa & Negativa & Negativa \\
\hline 11 & Sim & 90 & 35 & Negativa & Negativa & Negativa & Negativa \\
\hline
\end{tabular}

Legenda: UFC/g = Unidades Formadoras de Colônias por grama de produto.

As análises micológicas revelaram crescimento fúngico em 10 (90,9\%) amostras, sendo identificados: Rhodotorula spp. Exophialajeanselmei, Drechslera spp., Fonsecaea spp., Cuvularia spp.e Mycelia sterilia. A Tabela 2 apresenta as espécies fúngicas isoladas em cada uma das amostras analisadas.

Tabela 2. Espécies fúngicas isoladas nas bases faciais cosméticas líquidas e industrializadas, comercializadas em Goiânia, GO.

\begin{tabular}{ll}
\hline Base Facial & Espécie Fúngica \\
\hline 01 & Mycelia sterilia \\
02 & Mycelia sterilia \\
03 & Exophiala jeanselmei e Drechslera spp. \\
04 & Mycelia sterilia \\
05 & Mycelia sterilia \\
06 & Negativa \\
07 & Mycelia sterilia \\
08 & Fonsecaea spp. \\
10 & Mycelia sterilia \\
11 & Rhodotorula spp. \\
&
\end{tabular}




\section{Discussão}

A ANVISA estabelece que as contagens de microrganismos mesófilos aeróbios totais, bolores e leveduras não podem ultrapassar 102 UFC/g ou mL do produto, sendo o limite máximo aceitável de $5 \times 102 \mathrm{UFC} / \mathrm{g}$ ou $\mathrm{mL}$, e que necessitam indicar ausência para a pesquisa de coliformes, Staphylococcus aureus e Pseudomonas aeruginos $a^{9,16}$. A detecção de microrganismos nos produtos cosméticos indicam falhas no processamento, que podem ocorrer desde a aquisição da matéria prima até a apresentação do produto no comércio ${ }^{21}$.

No presente estudo, $18,2 \%$ das bases faciais cosméticas líquidas analisadas apresentaram contagem de colônias de microrganismos mesófilos aeróbios acima do limite máximo permitido pela ANVISA ( $5 \times 10^{2} \mathrm{UFC} / \mathrm{g}$ ou $\mathrm{mL}$ ) e $90,9 \%$ das amostras apresentaram contaminação por fungos anemófilos, embora nesse caso específico da pesquisa de bolores e leveduras, as culturas revelaram contagem de colônias abaixo do limite máximo considerado aceitável pela ANVISA (5×102 UFC/g ou $\mathrm{mL}$ ). Esses achados evidenciam a necessidade da garantia da qualidade microbiológica das embalagens e nas fases do processamento do produto por parte da indústria, bem como atenção do consumidor no momento da aquisição, em relação ao aspecto visual e ao prazo de validade estabelecido pelo fabricante. No geral, as amostras apresentaram resultados satisfatórios quanto aos critérios microbiológicos, mas vale ressaltar que melhorias no cumprimento das boas práticas de fabricação por parte das indústrias é importante no sentido de proporcionar maior segurança aos consumidores.

Mageste et al. ${ }^{22}$ realizaram um estudo em ambiente de produção de uma empresa farmacêutica de Juiz de Fora, MG, obtendo resultados entre 26 e 53 UFC/hora, com o limite máximo estabelecido de 50 UFC/hora para contaminantes do ar. Dentre suas comparações, os autores verificaram que o baixo índice de contaminantes encontrados se deu pelo uso de vestimentas específicas, equipamentos de proteção individual (EPI), treinamentos de funcionários, monitoramento, e higienização adequada dos ambientes.

No trabalho de Cucé et al. ${ }^{23}$, Mycelia sterilia, Cladosporium spp. e Penicillium spp. foram os gêneros fúngicos mais isolados em instalações hospitalares. O surgimento e o crescimento destes fungos anemófilos foram influenciados pelas condições ambientais, tais como umidade e temperatura, bem como pelos métodos de limpeza empregados nos ambientes e fluxo de pessoas nos locais estudados. Sendo a higiene e a sanitização, tanto do ar ambiente quanto dos trabalhadores, máquinas e utensílios, o que mantêm e garante a qualidade do produto ${ }^{10,24}$.

Produtos com maior teor de água em sua composição são mais vulneráveis à contaminação microbiana. Se ocorrer alguma contaminação ambiental, produtos com essa característica podem se tornar meios de cultura para diversos microrganismos ${ }^{21}$. E mesmo a pele sendo uma barreira natural devido ao seu $\mathrm{pH}$ e seus componentes lipídicos, os quais promovem a inibição de diferentes microrganismos de sua microbiota autóctone, fungos e bactérias mesófilas aeróbias podem penetrar através de lesões na pele ${ }^{25}$.

Embora considerados contaminantes ambientais, alguns dos fungos que foram observados nessa pesquisa podem trazer prejuízos à saúde humana, principalmente em se tratando de indivíduos imunossuprimidos. O fungo Exophiala jeanselmei é um exemplo de espécie ambiental comum, tendo como algumas manifestações clínicas micetomas, infecções cutâneas e cistos subcutâneos que podem penetrar na pele ${ }^{26}$. Já Cuvularia spp. é uma espécie de afecção cutânea, fungo nãodermatófito, que raramente implica em patologia humana, estando descritos raros casos de inoculação traumática ou fenômenos alérgicos ${ }^{27}$.

Já a Rhodotorula spp. é uma levedura emergente, que apesar de fazer parte da microbiota normal transitória, pode ocasionar infecção em humanos ${ }^{28}$. Quanto à Fonsecaea spp., é considerada um importante agente etiológico da cromoblatomicose, uma micose subcutânea que pode assumir um caráter oportunista, assim como a Drechslera spp., que pode acometer indivíduos imunossuprimidos ${ }^{29}$.

É esperado que os cosméticos atendam aos padrões microbiológicos determinados pela legislação brasileira e cumpram a aplicação das boas práticas de fabricação, pois os fungos e as bactérias, quando presentes em grande quantidade nas formulações, podem desenvolver danos quando os produtos são aplicados em regiões da pele, sobretudo quando lesões estão presentes, e perder a estabilidade da formulação do produto ${ }^{10,24}$.

\section{Conclusão}

Em conclusão, o presente estudo evidenciou a necessidade de garantir a qualidade e a higiene das bases cosméticas faciais líquidas industrializadas, comercializadas em Goiânia, GO. Em sua maioria, as amostras atenderam à legislação brasileira em relação ao controle de qualidade microbiológico, embora duas $(18,2 \%)$ amostras analisadas tenham apresentado contagem de colônias de microrganismos mesófilos aeróbios acima do limite máximo permitido pela ANVISA e o percentual de amostras contaminadas com fungos foi considerado elevado em 10 amostras (90,9\%), mesmo com a contagem de colônias de bolores e leveduras encontrando-se abaixo do limite máximo considerado aceitável pela ANVISA. Contudo, vale ressaltar a importância da adoção de melhorias por parte das indústrias quanto ao cumprimento das boas práticas de 
fabricação, no intuito de assegurar a segurança microbiológica destes cosméticos aos seus consumidores.

\section{Referências}

1. Lyrio ES, Ferreira GG, Zuqui SN, Silva AG. Recursos vegetais em biocosméticos: conceito inovador de beleza, saúde e sustentabilidade. [Trabalho de Conclusão de Curso]. Vila Velha: Centro Universitário Vila Velha, Curso de Graduação Tecnologia em Estética, 2011.

2. Santana A, Okamotto PT, Barboza LC, et al. Cosméticos à base de produtos naturais. 1a Edição. ESPM; 2008.

3. Barbosa ALF. Avaliação da eficácia antimicrobiana do monoéster de C-8 xilitol como alternativa conservante para produtos cosméticos [Dissertação de mestrado]. Campinas: Universidade Estadual de Campinas, Faculdade de Ciências Médicas. 2010.

4. O surpreendente mercado de beleza no Brasil [Internet]. NegociosSC. 2021 [cited 2021 Dec 10]. Available from: https://negociossc.com.br/blog/o-surpreendente-mercado-de-beleza-no-brasil-e-seu-publico.

5. Fritz $M$, Souza, CG. Inovação na indústria de cosméticos - Casos de empresas do setor. Anais do XXXIV COBENGE; 2006;1-16.

6. Benvenutti AS, Veiga A, Rossa LS, Murakami F. Avaliação da qualidade microbiológica de maquiagens de uso coletivo. 2016;(20):159-163.

7. Noor R, Zerin N, Das KK, Nittu, LN. Safe usage of cosmetics in Bangladesh: a quality perspective based on microbiological attributes. Journal of Biological Research-Thessaloniki. Post. 09 September 2015.

8. lensen T, Vogler J. Controle de qualidade microbiológico de produtos cosméticos brasileiros: Elaboração de um protocolo. Anais do EVINCIR; 11-06-2021.

9. Brasil, Ministério da Saúde 2013. Agência Nacional de Vigilância Sanitária: Aprova o Regulamento Técnico de Boas Práticas de Fabricação para Produtos de Higiene Pessoal, Cosméticos e Perfumes, e dá outras providências. Estado De Goiás, Assembleia Legislativa Do Estado De Goiás 1999. Lei n 9.782.

10. Mota VAM, Junior JAO, Chiari-Andréo BG. O controle da contaminação microbiológica de produtos magistrais. Revista Brasileira Multidisciplinar. 2017.

11. Pinto TJA, Kaneko TM, Ohara MT. Controle biológico de qualidade de produtos farmacêuticos, correlatos e cosméticos. 2003;(41):2-1.

12. Jorge AIS, Oliveira AP, Oliveira RP. Avaliação da eficácia de conservantes em preparações comerciais para higiene íntima - Experiência Profissionalizante na vertente de Investigação e Farmácia Comunitária. [Dissertação de mestrado]. Covilhã: Universidade da Beira Interior, Ciências da Saúde.

13. Neza E, Centini M. Microbiologically Contaminated and Over Preserved Cosmetic Products According Rapex. Department Biotechnologies, Chemistry and Pharmacy, University of Siena, Via Aldo Moro 2, Siena.

14. Shaqra A, Al-Groom RM. Microbiological quality of hair and skin care cosmetics manufactured in Jordan. Elsevier; 2012.

15. Brasil, Ministério da Saúde 1999. Agência Nacional de Vigilância Sanitária: Considerando a necessidade de estabelecer parâmetros para controle microbiológico de produtos cosméticos. Estado de Goiás, Assembleia Legislativa do Estado de Goiás. 1999. Lei n 481.

16. Agência Nacional de Vigilância Sanitária. Farmacopeia brasileira. 6.ed., v.1. Brasília: ANVISA, 2019.

17. Amaral R, et.al. $1^{\text {a }}$ edição. Guia de microbiologia. [S.I]. 2015.

18. Bou-Chacra NA, Ohara MT. Validação de método para avaliação de qualidade sanitária de preparação cosmética de base lipofílica. [Dissertação]. São Paulo: Universidade de São Paulo, Departamento de Farmácia, Faculdade de Ciências farmacêuticas; 2003.

19. Vasconcelos TYL, Medeiros DPF, Nascimento AA. A inibição do sistema conservante de duas emulsões o/a por Polissorbato 80. Infarma. 2015;(27): 221-225

20. Brandão R, Gomes A, Batista F, Borba T, Fernandes C, Júnior A, Souza S, Pinto M. Análise microbiológica de bases cosméticas faciais. [Trabalho de conclusão de curso] Montes Belos: Faculdade Montes Belos, Curso de farmácia. 2014.

21. Kasvi. Qualidade microbiológica em Produtos Cosméticos. [Internet]. São José do Pinhais - PR. [atualizado em 2016 Mar.24; citado em 2021 Set 22]. Disponível em: https://kasvi.com.br/qualidade-microbiologicacosmeticos/.

22. Mageste JO, Pereira TCD, Silva GA, Barros RAM. Estudo da microbiota fúngica anemófila de uma indústria farmacêutica de Juiz De Fora - MG. 2012; (1) 1-17.

23. Cucé LC, Andrade FA, Salebiam A, Vaccari EMH. Flora anemófila em ambiente hospitalar. Anais Brasileiros de Dermatologia, 1993; (68) 201-204.

24. Weber LZ, Frasson APZ. Controle microbiológico do ambiente interno de farmácias de manipulação. Revista Contexto \& Saúde. 2013;(9)39-44.

25. Salgado YCS. Patologia das doenças. Ponta Grossa. 2018. 
26. Pereira ACSF, Júnior PPS, Milian EP. [Internet]. Natal- RN. Eumicetoma e actinomicetoma: uma breve revisão da literatura. Universidade Federal do Rio Grande do Norte, Natal, RN. [Recebido em 2017 Out; Aprovado em 2018 nov.]. Disponível em: http://www.rbac.org.br/ artigos/eumicetoma-e-actinomicetoma-uma-breverevisao-da-literatura/

27. Antoniassi NAB, Corrêa AMR, Becker C, Sanchês EMC, Ferreiro L, Driemeier D. 2010. Feohifomicose cutânea causada por Curvularia sp. em um equino. Acta ScientiaeVeterinariae.2010; (1): 73-76.

28. Alves KP. 2019. Realidade e desafios de infecções emergentes por Rhodotorula spp. em pacientes hospitalizados. [Trabalho de Conclusão de Curso]. Florianópolis: Universidade Federal de Santa Catarina, Curso de Farmácia; 2019.

29. Bravim MS. 2009. Fungos associados às onicomicoses: prevalência e suscetibilidade a drogas antifúngicas. [Dissertação apresentada ao Programa de Pós-Graduação em Patologia das doenças infecciosas]. Vitória: Universidade Federal do Espírito Santo; 2009. 